\title{
Two new species of Quasithelazia Maplestone, 1932 (Nematoda: Acuariidae) from Malaysia, with an amended diagnosis and review of the genus
}

\author{
Yasen Mutafchiev $\cdot$ Jean Mariaux • \\ Boyko B. Georgiev
}

Received: 10 February 2014/ Accepted: 12 March 2014

(C) Springer Science+Business Media Dordrecht 2014

\begin{abstract}
Quazithelazia rostrata n. sp. from Ceyx erithaca (L.) (type-host) and Alcedo euryzona Temminck (Coraciiformes, Alcedinidae) and Q. alata $\mathrm{n}$. sp. from Enicurus ruficapillus Temminck (Passeriformes, Muscicapidae) are described from vicinities of Gombak Biological Station, Selangor, Malaysia; both species are parasitic under the koilin lining of the gizzard. Paratypes of Schistogendra pelargopsis Nandi, De \& Majumdar, 1985, a parasite of Pelargopsis capensis (L.) (Alcedinidae) from India, are redescribed and the species is recognised as a junior synonym of the type-species of Quasithelazia, $Q$. tenuis Maplestone, 1932 (new synonymy), a species originally described from Halcyon smyrnensis (L.) (Alcedinidae) in India. An amended diagnosis of the genus Quasithelazia Maplestone, 1932 is proposed. Currently, this genus includes eight species occurring in the Old World, six of them parasitic in kingfishers (Alcedinidae) and two species parasitic in flycatchers
\end{abstract}

Y. Mutafchiev $(\bowtie) \cdot$ J. Mariaux

Natural History Museum of Geneva, 1 Route de

Malagnou, 1211 Geneva 6, Switzerland

e-mail: mutafchiev@gmail.com

Y. Mutafchiev $\cdot$ J. Mariaux

Department of Genetics and Evolution, University of Geneva, Boulevard d'Yvoy 4, 1205 Geneva, Switzerland

Y. Mutafchiev · B. B. Georgiev

Institute of Biodiversity and Ecosystem Research, Bulgarian Academy of Sciences, 2 Gagarin Street, 1113 Sofia, Bulgaria
(Muscicapidae). These include, inter alia, Q. halcyoni n. comb. for Viktorocara halcyoni Ryzhikov \& Khokhlova, 1964 from Halcyon smyrnensis and $H$. pileata (Boddaert) in Vietnam and the Russian Far East, Q. microcordonis $\mathrm{n}$. comb. for Rusguniella microcordonis Schmidt \& Kuntz, 1971 from Halcyon coromanda major (Temminck \& Schlegel) in Taiwan and $Q$. multipapillata $\mathrm{n}$. comb. for Schistogendra multipapillata Zhang, 1993 from Tarsiger cyanurus (Pallas) (Muscicapidae) in China. Comparative morphological data for Quasithelazia spp. are presented. Schistogendra oligopapillata Zhang \& An, 2002 from domestic ducks in China is considered a species incertae sedis.

\section{Introduction}

The classification of the family Acuariidae Railliet, Henry \& Sisoff, 1912 is mainly based on the morphology of anterior cuticular ornamentations (cordons, collarette or ptilina) that is used to distribute the genera among the three recognised subfamilies, i.e. Acuariinae Railliet, Henry \& Sisoff, 1912, Seuratiinae Chitwood \& Wehr, 1932 and Schistorophinae Travassos, 1918 (see Chitwood \& Wehr, 1934; Chabaud, 1975; Bain et al., 2014). Although such structures are lacking in the genera Paracuaria Rao, 1951 (Acuariinae) and Quasithelazia Maplestone, 1932 (Schistorophinae) as well as in one of the members of the genus Streptocara Railliet, Henry \& Sisoff, 1912 
(Seuratiinae), the systematic position of these taxa is inferred on the basis of the morphology of their deirids, buccal cavity and tail (Gibson, 1968; Chabaud, 1975; Bain et al., 2014).

Quasithelazia was erected within the subfamily Schistorophinae as a monotypic genus for $Q$. tenuis Maplestone, 1932, a species described on the basis of a single male nematode collected from the kingfisher Halcyon smyrnensis (L.) in India (Maplestone, 1932). Subsequently, this genus was considered a synonym of Schistorophus Railliet, 1916 (see Singh, 1949) or, in contradiction with the International Code of Zoological Nomenclature, of the more recently erected genus Viktorocara Guschanskaya, 1950 (see Skrjabin et al., 1965). Wong \& Lankester (1984) justified the validity of Quasithelazia and recognised it as a senior synonym of Schistogendra Chabaud \& Russelot, 1956, a genus containing at that time two species parasitic in kingfishers, i.e. S. incisa Chabaud \& Rousselot, 1956 and S. caproni Bain \& Chabaud, 1965. Despite the well-grounded position of Schistogendra as a junior synonym of Quasithelazia (see Wong \& Lankester, 1984), subsequent authors described three further species as members of Schistogendra, i.e. S. pelargopsis Nandi, De \& Majumdar, 1985, S. multipapillata Zhang, 1993 and S. oligopapillata Zhang \& An, 2002 (Nandi et al., 1985; Zhang, 1993; Zhang \& An, 2002).

Recent studies of helminth parasites of birds from the continental part of Malaysia have revealed unknown species of the genus Quasithelazia. The aim of the present paper is to describe two new species of Quasithelazia parasitic in kingfishers (Alcedinidae) and flycatchers (Muscicapidae). We also revise the taxonomic position of several related taxa and propose an amended generic diagnosis of the genus Quasithelazia.

\section{Materials and methods}

During a field trip by two of the present authors (JM and BBG) in Selangor, Malaysia (30 July-11 August 2010), six Ceyx erithaca (L.) (Coraciiformes, Alcedinidae), three Alcedo euryzona Temminck (Coraciiformes, Alcedinidae) and eight Enicurus ruficapillus Temminck (Passeriformes, Muscicapidae) were captured by mist nets and dissected immediately after their death. Nematodes collected under the koilin lining of the gizzard were fixed and stored in $70 \%$ ethanol. In addition, type-specimens of Schistogendra pelargopsis Nandi, De \& Majumdar, 1985 from the collection of the Muséum National d'Histoire Naturelle, Paris (MNHN) were studied.

For light-microscopy observations, specimens were cleared and examined as temporary mounts in lactophenol. Specimens (one male and one female from C. erithaca) used for SEM observations were dehydrated in an ethanol series, immersed in hexamethyldisilazane for $20 \mathrm{~min}$, air-dried, coated with gold in Cressington 108-Auto coater and examined using a Zeiss DSM 940A microscope at $15 \mathrm{kV}$.

All measurements are in micrometres unless otherwise indicated. Metrical data are given as the range, with the mean and the number of measurements taken (n) in parentheses. The following indices were used: $\mathrm{I}_{\mathrm{mOE} / \mathrm{gOE}}$, length of muscular oesophagus/length of glandular oesophagus; $\mathrm{I}_{\mathrm{OE} / \mathrm{BL}}$, length of oesophagus/body length; $\mathrm{I}_{\mathrm{LSP} / \mathrm{RSP}}$, length of left spicule/length of right spicule; $\mathrm{I}_{\mathrm{LSB} / \mathrm{LSH}}$, length of left spicule blade/ length of left spicule handle; $\mathrm{I}_{\mathrm{V} / \mathrm{BL}}$, distance from anterior end to vulva/body length.

\section{Quazithelazia rostrata $\mathbf{n} . \mathbf{s p}$.}

Type-host: Ceyx erithaca (L.) (Coraciiformes: Alcedinidae).

Other hosts: Alcedo euryzona Temminck (Coraciiformes, Alcedinidae).

Type-locality: Gombak Field Station of the University of Malaya, Selangor, Malaysia $\left(3^{\circ} 19^{\prime} 12^{\prime \prime} \mathrm{N}\right.$, $\left.101^{\circ} 45^{\prime} 0^{\prime \prime} \mathrm{E}\right)$.

Site in host: Under the koilin lining of the gizzard.

Prevalence: In C. erithaca, 67\% (4/6); in A. euryzona, $67 \%(2 / 3)$.

Intensity of infection: In C. erithaca, 3-12 (mean 7) individuals; in A. euryzona, 2 individuals.

Type-specimens: Holotype: MHNG-INVE-85992 (male); Paratypes (from C. erithaca only): MHNGINVE-85994 (3 males and 1 female), MHNG-INVE85995 ( 3 males and 2 females), MHNG-INVE-85996 (1 female), MHNG-INVE-86088 (1 female, SEM stub), MHNG-INVE-86089 (1 male, SEM stub), MHNG-INVE-86090 (1 female), MHNG-INVE86091 (1 male), MHNG-INVE-86092 (anterior and posterior extremities of a single female used for DNA), IBER 001.117 (3 males and 2 females), IBER 001.118 ( 2 females), USNPC 107982.00 ( 2 males and 3 females). 
Other specimens: Ex A. euryzona, MHNG-INVE86093 (1 male and 1 female), MHNG-INVE-86094 (2 males).

Etymology: Rostrata = "beaked"; the name of the new species refers to the peculiar anterior extremity of its pseudolabia.

\section{Description (Figs. 1, 2)}

General [Based on specimens from C. erithaca.] Small-sized acuariid nematodes with thin body. Anterior end with 2 pseudolabia; each pseudolabium with prominent $c .3$ long rostrum-like anterior apex with abrupt tip and bearing single amphid and pair of inconspicuous papillae; pair of plate-like teeth present, situated on lobes of internal side of each pseudolabium (Figs. 1A, B, 2A-C). Cuticular ornamentation in form of cordons, collarette or ptilina absent; 1 subventral and 1 subdorsal lobe on each pseudolabium formed by short transverse incision (Fig. 2A, B). Sublabia not differentiated. Body cuticle with fine transverse striations. Deirids minute, $c .1-2$ long (Fig. 2D), situated near level of junction of buccal cavity and muscular oesophagus. Buccal cavity long, with conspicuous cross-striations. Muscular and glandular portion of oesophagus distinct. Intestine adjacent to oesophagointestinal junction, with thick walls (Fig. 1C). Nervering surrounds anterior portion of muscular oesophagus. Excretory pore posterior to nerve-ring. Phasmids subterminal (Figs. 1D, J, 2H).

Male [Based on 10 specimens.] Body length 5.6-6.7 (6.2) $\mathrm{mm}$. Maximum body width at level of oesophagointestinal junction, 54-66 (58); body width at level of cloaca 32-38 (35). Tail 56-70 (64) long. Cuticle 4-5 thick, with transverse striations, $c .3$ apart. Deirids and excretory pore at 106-136 (121) and 162-180 (169), respectively, from anterior extremity. Buccal cavity 106-122 (113) long, 4 wide. Muscular oesophagus 607-735 (679) long, 54-57 (56) wide at mid-length. Glandular oesophagus 1,390-1,620 (1,492) long, with maximum width in posterior portion 34-47 (41). Nervering at 128-141 (133) from anterior extremity. Testis reflection 3.0-3.6 (3.3) $\mathrm{mm}$ from anterior extremity. Caudal alae wide, membranous, 291-327 (307) long, forming rounded posterior end of tail in dorsoventral view (Fig. 1D). Precloacal papillae represented by 10 pairs of subventral pedunculate papillae arranged equidistantly and single ventral precloacal papilla (Fig. 1D,
E). Postcloacal papillae 6 pairs: 5 subventral pairs and 1 small pair, situated between bases of last pair of subventral papillae. Left spicule 278-399 (370) long, composed of handle 131-165 (150) long and blade 147-255 (219) long, with thin velum at distal tip (Fig. 1D-F). Right spicule robust, 74-85 (80) long, with blunt tip, armed with 2 subapical cusps; in addition, 2 proximal cusps present (Figs. 1G, 2E). $\mathrm{I}_{\mathrm{mOE} / \mathrm{gOE}}=$ $0.41-0.51 \quad(0.46) ; \quad \mathrm{I}_{\mathrm{OE} / \mathrm{BL}}=0.33-0.38 \quad(0.35) ; \mathrm{I}_{\mathrm{LSP} /}$ RSP $=3.77-5.01(4.56) ; \mathrm{I}_{\mathrm{LSB} / \mathrm{LSH}}=1.13-1.78(1.46)$.

Female [Based on 10 specimens.] Body 9.9-16.2 (12.9) $\mathrm{mm}$ long, with maximum body width at midbody, 73-105 (88); body width at level of vulva 66-99 (78); body width at level of anus, 32-46 (38). Deirids and excretory pore at 112-141 (123) and 156-187 (172), respectively, from anterior extremity. Buccal cavity 114-132 (121) long, 4-5 wide. Muscular oesophagus 702-845 (772) long, 11-17 (13) wide at mid-length. Glandular oesophagus 1,600-1,979 $(1,755)$ long, with maximum width in posterior portion 45-60 (50). Rectum, very wide, with thin walls (Fig. $1 \mathrm{~J})$. Cuticle 5-7 thick, with transverse striations, 4-5 apart. Vulva at 6.2-9.5 (7.8) $\mathrm{mm}$ from anterior extremity (Fig. 2F). Reproductive system didelphicamphidelphic, not extending beyond level of oesophago-intestinal junction (Fig. 1I). Vagina directed posteriorly, consisting of vagina vera 97-127 (115) long (measured following its lumen), separated from vagina uterina by sphincter; vagina uterina 81-143 (115) long, with thick muscular walls (Figs. 1H, 2G). Tail conical, 68-104 (89) long, curved dorsally, with rounded tip (Figs. $1 \mathrm{~J}, 2 \mathrm{H}$ ). Eggs oval, 34-37 × 21-23 $(36 \times 22)$, containing developed first-stage larva (Fig. $1 \mathrm{~K}) . \quad \mathrm{I}_{\mathrm{mOE} / \mathrm{gOE}}=0.43-0.47 \quad(0.44) ; \mathrm{I}_{\mathrm{OE} / \mathrm{BL}}=$ $0.16-0.23(0.20) ; \mathrm{I}_{\mathrm{V} / \mathrm{BL}}=0.55-0.68(0.61)$.

For metrical data of the specimens from Alcedo euryzona see Table 1.

\section{Remarks}

The samples from $C$. erithaca and A. euryzona, described here, resemble one another in their morphological characters (Table 1). They obviously belong to the same new species and are characterised by a morphology corresponding to the generic diagnosis of Quasithelazia. Therefore, we name it Quasithelazia rostrata $\mathrm{n}$. sp. The new species differs from all its congeners by its (i) unique pseudolabia characterised by 


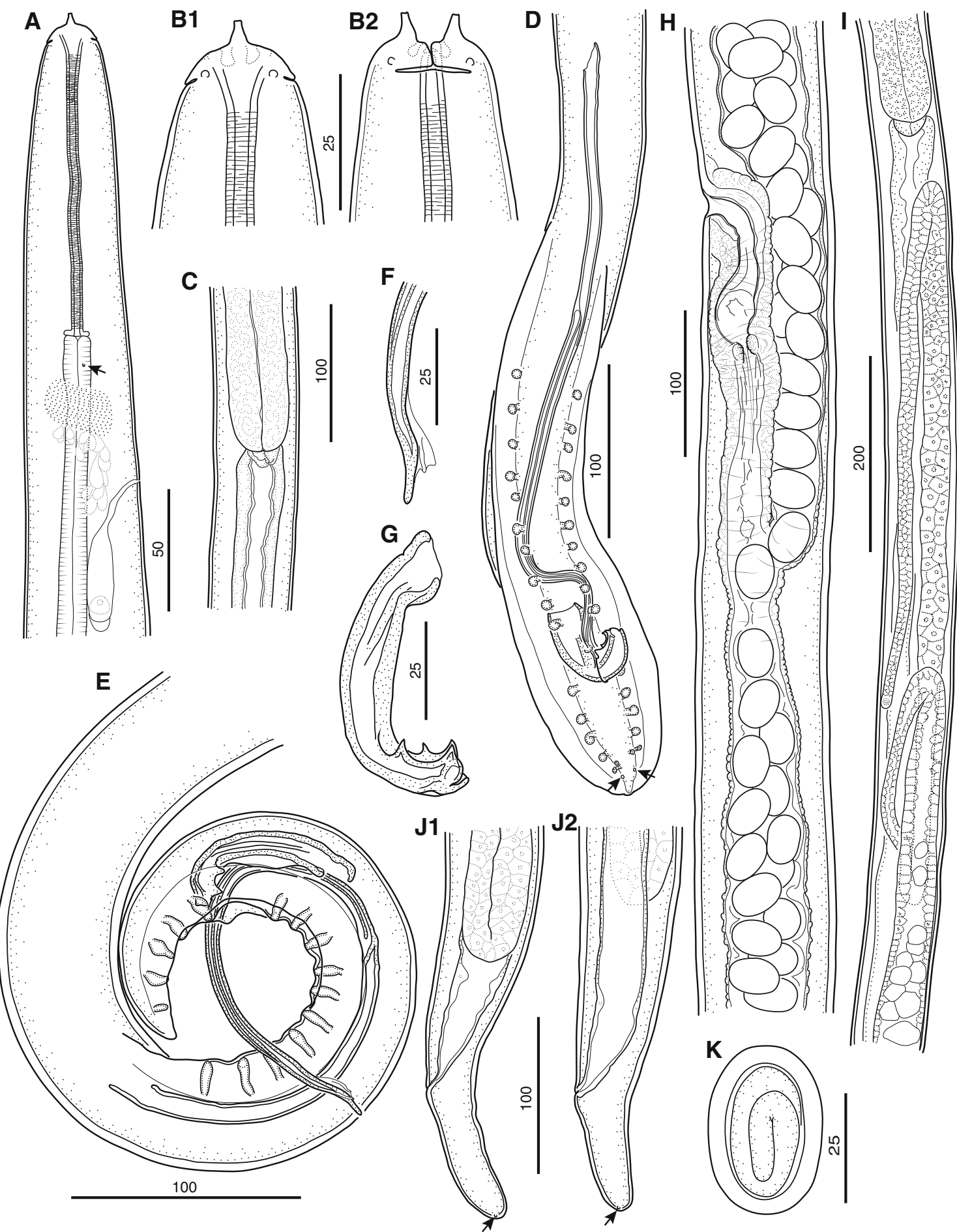

Fig. 1 Quasithelazia rostrata $\mathrm{n}$. sp. A, Anterior end, female, lateral view, note deirid (arrow); B, Cephalic region, female, lateral (B1) and dorsoventral (B2) view; C, Region of oesophago-intestinal junction, male, lateral view; D, Posterior end, male, ventral view, note phasmids (arrows); E, Posterior end, male, dextral view; F, Distal end of left spicule, dextral view; G, Right spicule, dextral view; H, Vagina; I, Region of anterior ovarium; J, Female posterior ends, lateral view, note phasmids (arrows); K, Egg. Scale-bars are in micrometres 

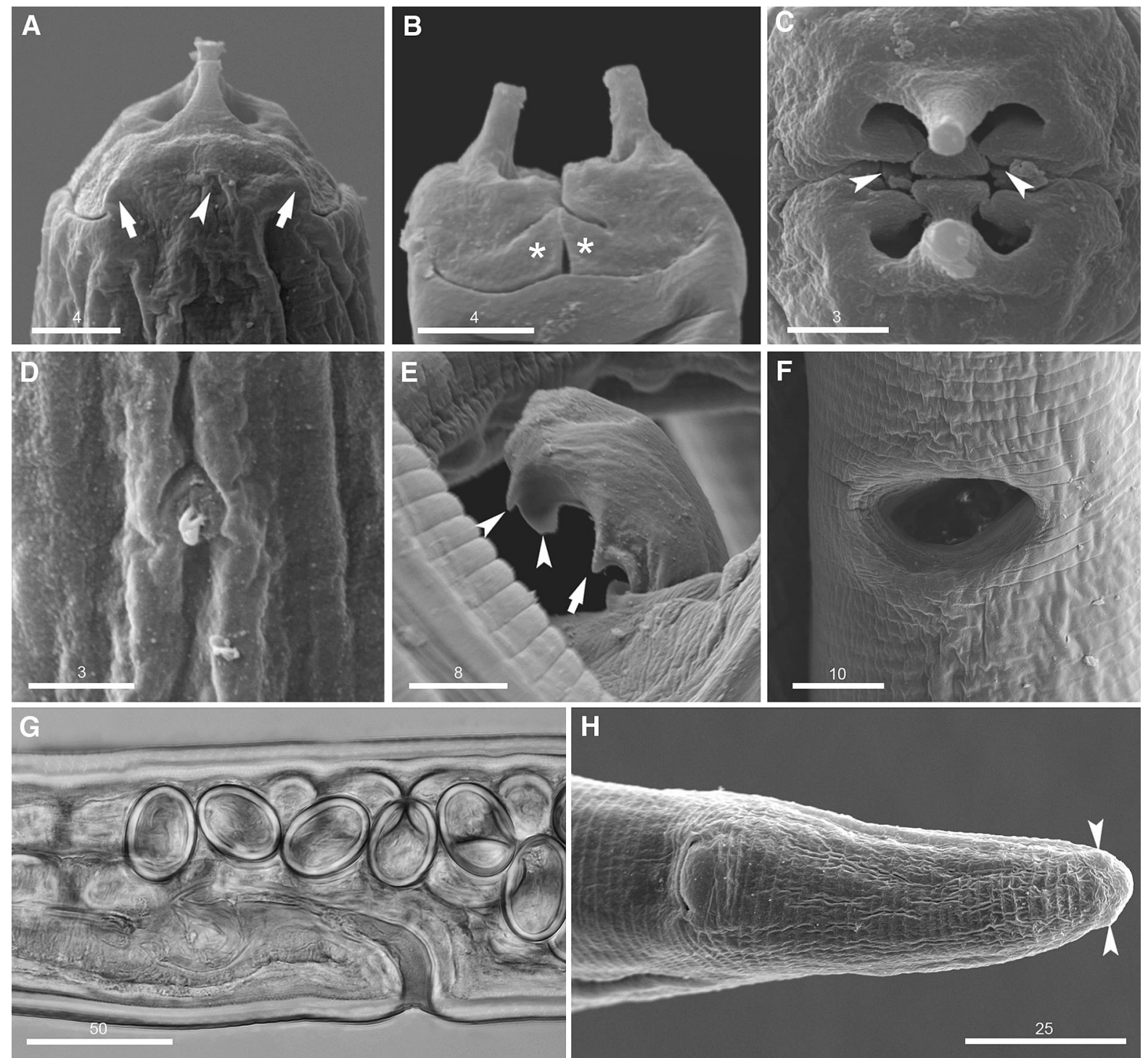

Fig. 2 Quasithelazia rostrata n. sp. A, Cephalic region, female, lateral view, note amphid (arrowhead) and cephalic papillae (arrows), SEM; B, Cephalic region, male, dorsoventral view, note lobes of pseudolabia (asterisks), SEM; C, Anterior end, female, apical view, SEM; D, Deirid, SEM; E, Distal part of right spicule, dextral view, note two subapical cusps (arrowheads) and one of two posterior cusps (arrow), SEM; F, Vulva, SEM; G, Region of vagina vera, DIC light-micrograph; H, Female tail, ventral view, note position of phasmids (arrowheads), SEM. Scale-bars are in micrometres

prominent, rostrum-like anterior apices with abrupt tips; (ii) longer glandular oesophagus (Table 1); (3) ten pairs of precloacal papillae vs 11-16 pairs in other Quasithelazia spp. (Table 1). In addition, the muscular oesophagus in Q. rostrata n. sp. is shorter than that of Q. alata $\mathrm{n}$. sp., but markedly longer than that of the remaining species in this genus; the ratio of the total length of oesophagus to the length of body is comparable only to that of Q. alata. Q. rostrata possesses spicules, which resemble in size only those of $Q$. incisa; however, these two species can be distinguished on the basis of morphological characters discussed above as well as by the shape of the female tail (Table 1).

\section{Quasithelazia alata $\mathbf{n}$. sp.}

Type-host: Enicurus ruficapillus Temminck (Passeriformes, Muscicapidae). 


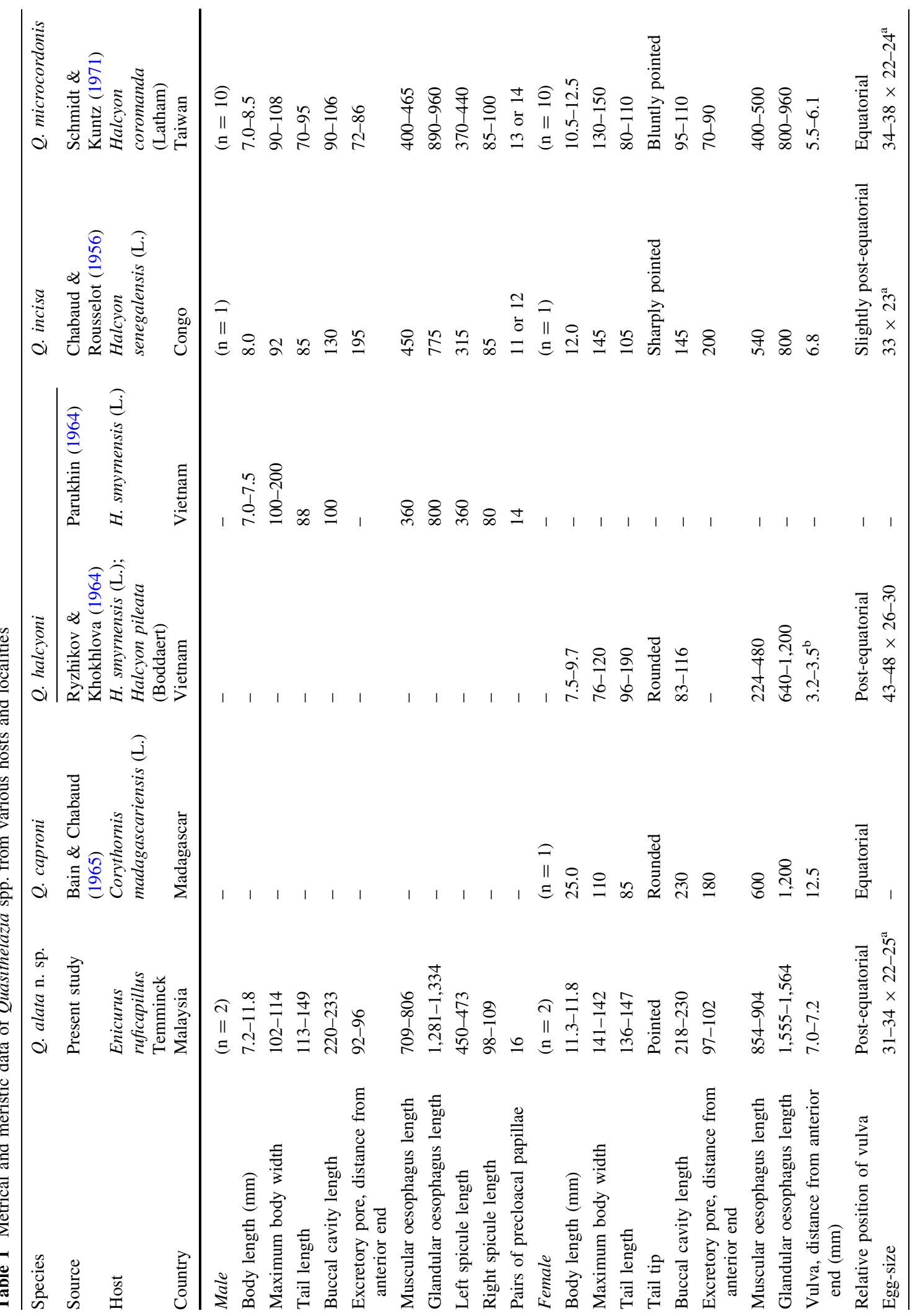




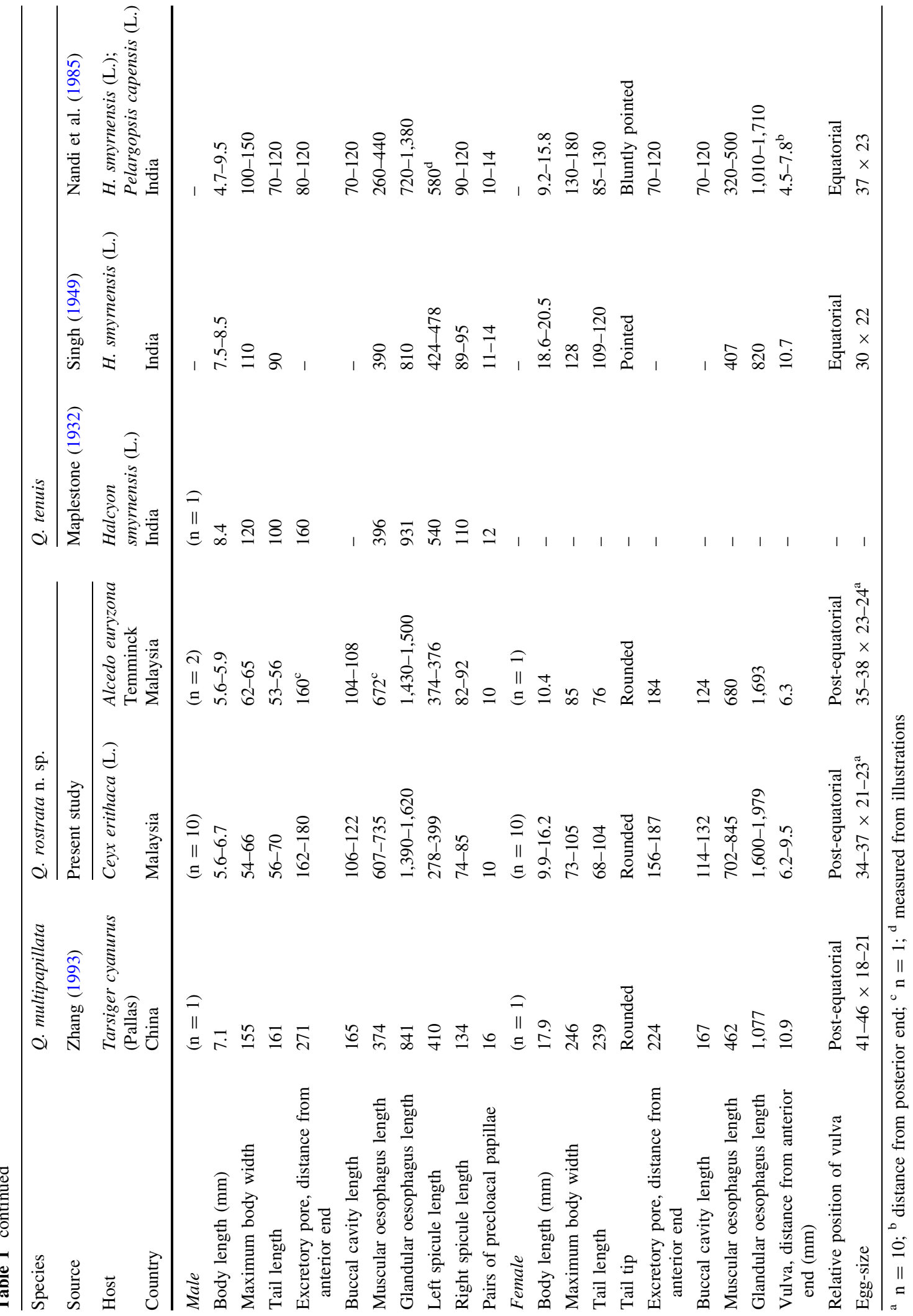


Type-locality: Gombak Field Station of the University of Malaya, Selangor, Malaysia $\left(3^{\circ} 19^{\prime} 12^{\prime \prime} \mathrm{N}\right.$, $\left.101^{\circ} 45^{\prime} 0^{\prime \prime} \mathrm{E}\right)$.

Site in host: Under the koilin lining of the gizzard.

Prevalence: $38 \%$ (3/8).

Intensity of infection: 1-2 (mean 1.7) individuals. Type-specimens: Holotype: MHNG-INVE-85997 (male); Paratypes: MHNG-INVE-85998 (1 female), MHNG-INVE-86095 (1 female), MHNG-INVE86096 (posterior extremity of a single female), MHNG-INVE-86097 (1 male).

Etymology: Alata = "winged"; the name of the new species refers to its well-developed lateral alae.

\section{Description (Figs. 3, 4)}

General Small-sized acuariid nematodes. Anterior end with 2 rounded pseudolabia, each bearing single amphid and pair of inconspicuous papillae (Fig. 3A-C). Sublabia not differentiated (Fig. 3B). Anterior cuticular ornamentation in form of cordons, collarette or ptilina absent. Body cuticle with fine transverse striations. Lateral alae prominent, up to 17 wide (in region of muscular oesophagus), extend from region posterior to pseudolabia along body, interrupted in region of deirids (Figs. 3B2, C, 4A). Deirids small, spine-like, c.2-3 long, situated anteriorly to muscular oesophagus. Buccal cavity long, with conspicuous cross-striations. Muscular and glandular portions of oesophagus distinct. Glandular oesophagus and intestine with similar width at their junction (Fig. 3D). Nerve-ring surrounds anterior part of muscular oesophagus. Excretory pore posterior to nerve-ring (Fig. 3A, C). Tail extremity pointed (Fig. 3E, J). Phasmids subterminal (Fig. 3J, G).

Male [Based on 2 specimens.] Body length $7.2-11.8 \mathrm{~mm}$. Maximum body width $102-149$, posterior to oesophago-intestinal junction. Body width at level of cloaca 59-60. Tail 113-149 long. Cuticle 5 thick, with transverse striations, c.2-3 apart. Lateral alae extending in posterior direction to caudal alae. Deirids and excretory pore at 66-78 and 220-233, respectively, from anterior extremity. Buccal cavity 92-96 long, 8 wide. Muscular oesophagus 702-806 long, 19 wide at mid-length. Glandular oesophagus 1,281-1,334 long, with maximum width at posterior portion 42-57. Nerve-ring at 154-157 from anterior body end. Testis reflection at $3.7-4.1 \mathrm{~mm}$ from anterior extremity. Caudal alae 439-462 long, with irregular dotted ornamentation beneath their ventral cuticular surface (Figs. 3E, 4B). Precloacal papillae represented by single ventral precloacal papilla and 16 pairs of subventral pedunculate papillae arranged equidistantly (Fig. 3E, F). Postcloacal papillae subventral; anterior 4 pairs pedunculate, papillae of fourth pair slightly smaller than those of first three pairs (Fig. 3E); fifth pair of papillae smaller, sessile; sixth pair slightly bigger (Fig. 3G). Left spicule 450-473 long, composed by handle 162-166 long and blade 289-307 long. Right spicule 98-109 long, robust (Fig. $3 \mathrm{H}$ ). $\mathrm{I}_{\mathrm{mOE} / \mathrm{gOE}}=0.55-0.60 ; \mathrm{I}_{\mathrm{OE} / \mathrm{BL}}=0.18-0.27$; $\mathrm{I}_{\mathrm{LSP} / \mathrm{RSP}}=4.14-4.8 ; \mathrm{I}_{\mathrm{LSB} / \mathrm{LSH}}=0.54-0.56$.

Female [Based on 2 specimens, except where otherwise indicated.] Body 11.3-11.8 mm long, with maximum body width in region of vulva 141-142; body width at level of anus 58-65. Tail conical, 68-104 long (Fig. 3J). Cuticle 5-6 thick, with transverse striations, c.3 apart. Lateral alae extending in posterior direction to midregion of tail (Fig. 3J). Deirids and excretory pore at 60-71 and 218-230, respectively, from anterior extremity. Buccal cavity 97-102 long. Muscular oesophagus 854-904 long, 23-24 wide at mid-length. Glandular oesophagus 1,555-1,564 long, with maximum width in posterior portion 54-55. Vulva at level of body cuticle, 7.0-7.2 $\mathrm{mm}$ from anterior extremity. Vagina directed posteriorly, consists of vagina vera $133(n=1)$ long (measured following its lumen), separated from vagina uterina by sphincter; vagina uterina $116(\mathrm{n}=1)$ long, with thick muscular walls (Fig. 3I). Reproductive system didelphic-amphidelphic, not exceeding in anterior direction level of oesophago-intestinal junction (Fig. 3D). Eggs oval, $31-34 \times 22-25 \quad(33 \times 24$, $\mathrm{n}=10$ ), containing developed first-stage larva (Fig. $3 \mathrm{~K}$ ). $\mathrm{I}_{\mathrm{mOE} / \mathrm{gOE}}=0.55-0.58 ; \mathrm{I}_{\mathrm{OE} / \mathrm{BL}}=0.20-0.22$; $\mathrm{I}_{\mathrm{V} / \mathrm{BL}}=0.61-0.62$.

\section{Remarks}

Quasithelazia alata n. sp. belongs to Quasithelazia because of the lack of any particular cuticular ornamentation of the head region and the presence of numerous pairs of precloacal papillae. However, this species differs from its congeners by having welldeveloped lateral alae and a longer muscular oesophagus (Table 1).

In having 16 pairs of precloacal papillae, Q. alata resembles $Q$. multipapillata (Zhang, 1933) n. comb. 


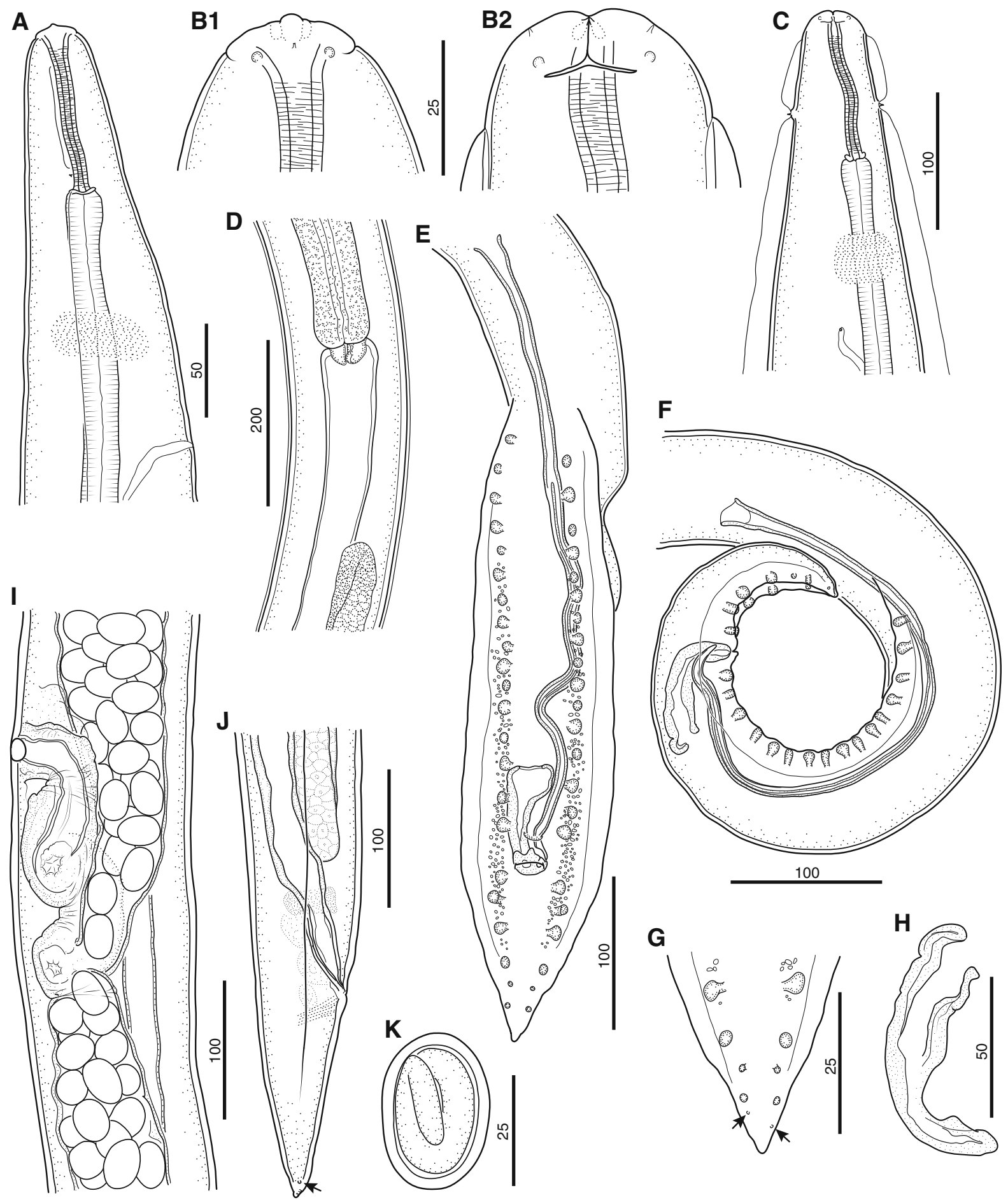

Fig. 3 Quasithelazia alata n. sp. A, Anterior end, male, lateral view; B, Cephalic region, female, lateral (B1) and dorsoventral (B2) view; C, Anterior end, ventral view, female; D, Region of oesophago-intestinal junction, dorsoventral view; E, Posterior end, male, ventral view; F, Posterior end, male, sinistral view; G, Tail extremity, male, ventral view, note phasmids (arrows); H, Right spicule, dextral view; I, Region of vagina, lateral view; J, Female, posterior end, lateral view, note phasmid (arrow); K, Egg. Scale-bars are in micrometres 

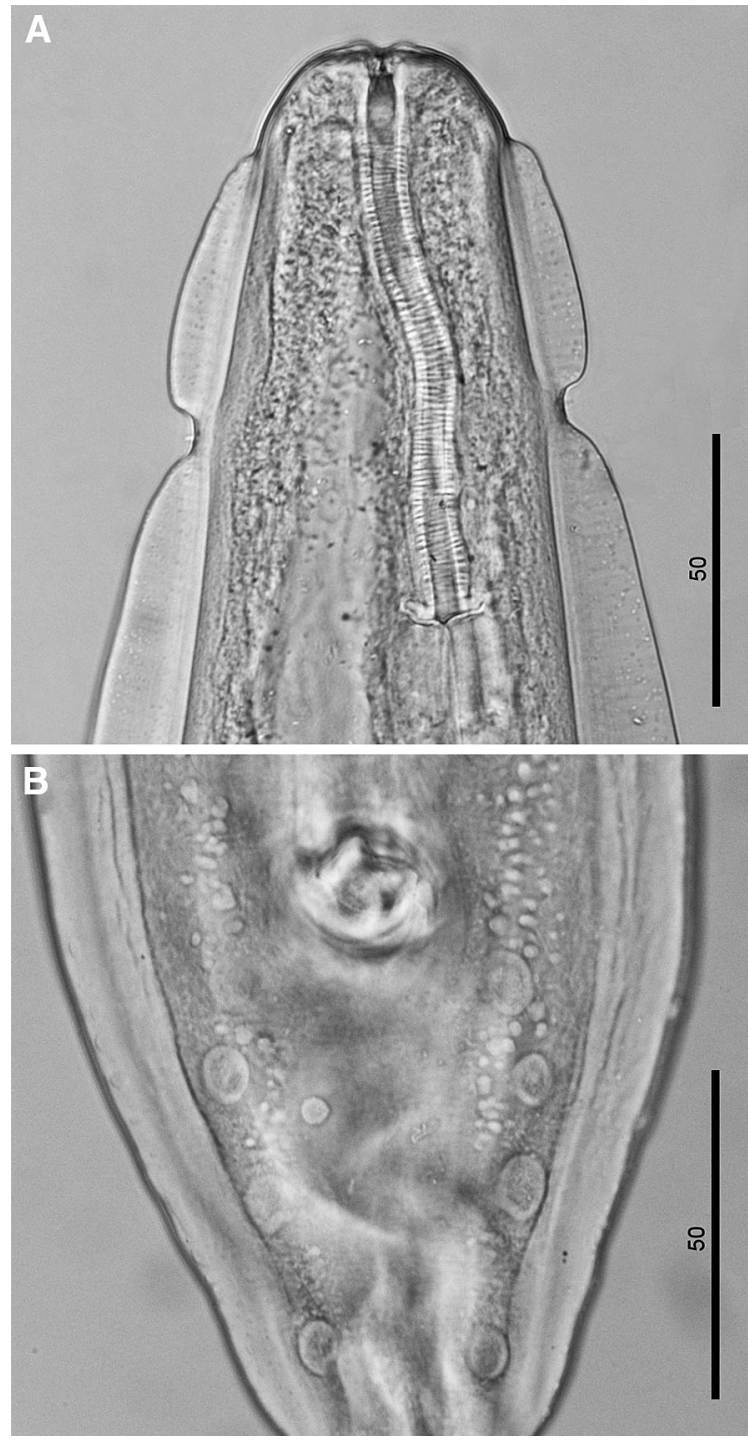

Fig. 4 Quasithelazia alata n. sp., light-micrographs. A, Anterior end of female, ventral view; $\mathrm{B}$, Posterior end of male, ventral view. Scale-bars are in micrometres

The new species can be distinguished from the latter by its rounded pseudolabia, the presence of lateral alae, the markedly longer muscular and glandular oesophagus, the shorter distance of excretory pore from anterior extremity, the shorter right spicule and the pointed tail in females (Table 1). These two species, in contrast to their congener parasitic in kingfishers, are found in flycatchers (Passeriformes: Muscicapidae).

The presence of lateral alae in $Q$. alata is unique among the Schistorophinae. However, similar alae are known in several genera of the Acuariinae, e.g. Cosmocephalus Molin, 2010, Aviculariella Wehr, 1931, Pelecanema Mutafchiev \& Georgiev, 2010 and Skrjabonocerca Shikhobalova, 1930 (see Shikhobalova, 1930; Diaz et al., 2005; Mutafchiev et al., 2009, 2010; Mutafchiev \& Georgiev, 2010) as well as in Ingliseria Gibson, 1968 of the subfamily Seuratiinae (see Diaz et al., 2009).

Redescription of type-specimens of Schistogendra pelargopsis Nandi, De \& Majumdar, 1985 (a junior synonym of Quasithelazia tenuis Maplestone, 1932, new synonymy)

Type-specimens: MNHN 1 male; 1 female (paratypes) from Pelargopsis capensis (L.) (Coraciiformes, Alcedinidae).

Site in host: Under the koilin lining of the gizzard. Locality: Golapbag, Bardhaman, India.

\section{Description (Fig. 5)}

General. Small-sized acuariid nematodes. Anterior end with 2 triangular pseudolabia with prominent triangular apex, each bearing single amphid and pair of papillae (Fig. 5A). Anterior cuticular ornamentation in form of cordons, collarette or ptilina absent; one subdorsal and one subventral lobe on each pseudolabium well-developed, formed by transverse incision. Pseudolabia not differentiated. Body cuticle with fine transverse striations. Deirids small, with rounded tip, $c .2-3$ long, situated at level anterior to muscular oesophagus. Buccal cavity long, with conspicuous cross-striations. Muscular and glandular portion of oesophagus distinct. Nerve-ring surrounds anterior part of muscular oesophagus. Excretory pore anterior to nerve-ring (Fig. 5A).

Male. Body length $5.5 \mathrm{~mm}$. Maximum body width posterior to oesophago-intestinal junction 95. Body width at level of cloaca 65. Tail 90 long. Cuticle 6 thick, with transverse striations, $c .5$ apart. Deirids and excretory pore at 63 and 67, respectively, from anterior extremity. Buccal cavity 112 long (convoluted, measured along curve), 7 wide. Muscular oesophagus 285 long, 13 wide at mid-length. Glandular oesophagus 637 long, 27 wide at mid-length. Nerve-ring at 5 from anterior end of muscular oesophagus. Caudal alae 406 long (Fig. 5B). 

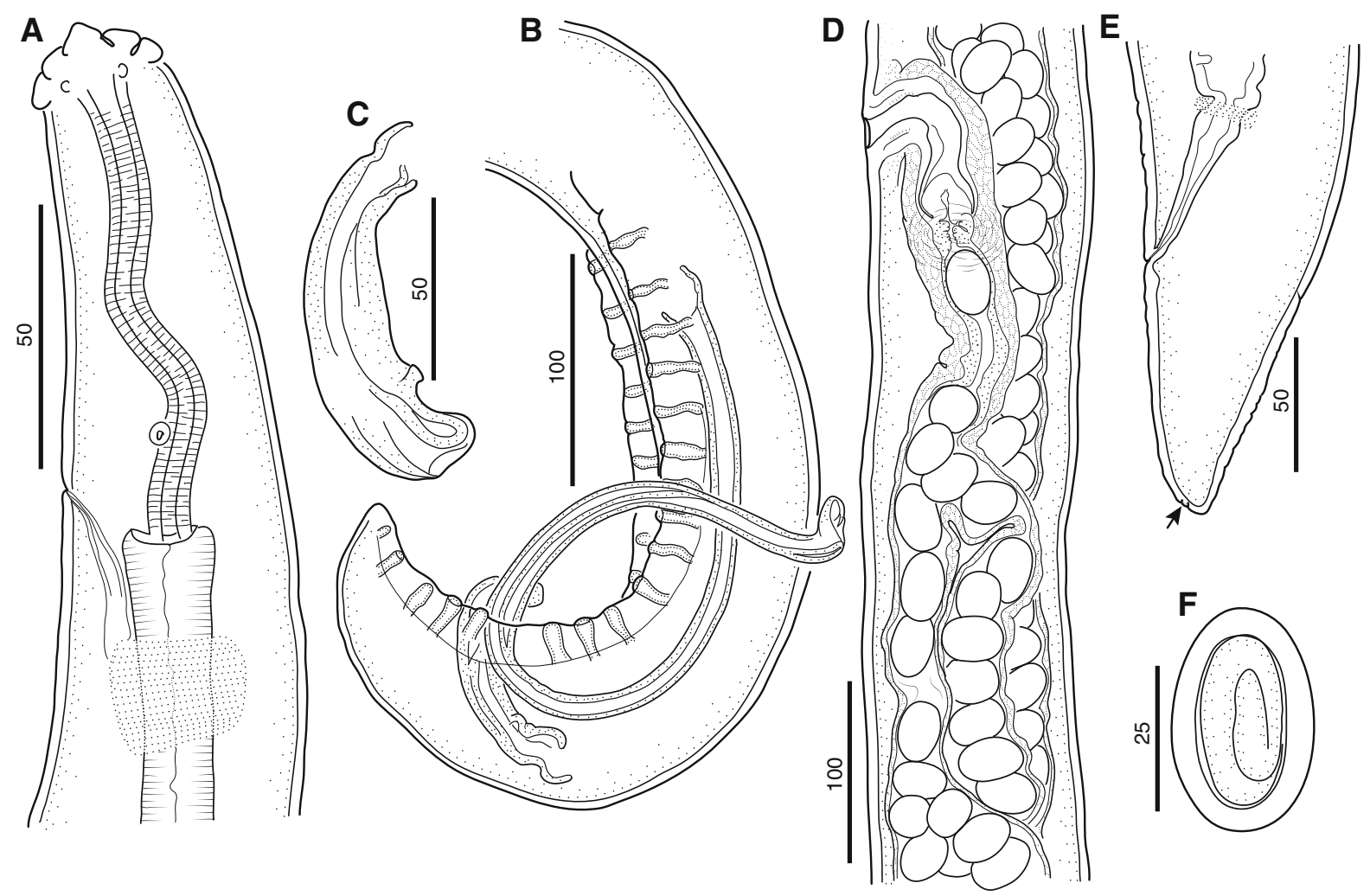

Fig. 5 Type-specimens of Schistogendra pelargopsis Nandi, De \& Majumdar, 1985, a junior synonym of Quasithelazia tenuis Maplestone, 1932. A, Anterior end of female, lateral view; B, Posterior end of male, sinistral view; C, Right spicule, dextral view; D, Region of vagina, lateral view; E, Female, posterior end, lateral view; F, Egg. Scale-bars are in micrometres

Precloacal papillae represented by 13 pairs of subventral pedunculate papillae, arranged equidistantly. Postcloacal pedunculate papillae 5 pairs, papillae of fifth pair smaller than anterior 4 pairs (the specimen was not studied in ventral view for the presence of sessile papillae). Left spicule 473 long, consisting of handle 273 long and blade 200 long. Right spicule 118 long, robust, with blunt tip and one posterior process (Fig. 5C).

Female. Body $13.1 \mathrm{~mm}$ long, with maximum width in region of vulva 123; body width at level of anus 59 . Tail conical, bluntly pointed, 86 long (Fig. 5E). Cuticle 6 thick, with transverse striations, 7-8 apart. Deirids and excretory pore at 77 and 92, respectively, from anterior extremity. Left postdeirid at $9.5 \mathrm{~mm}$ from anterior extremity. Buccal cavity 104 long, 7 wide. Muscular oesophagus 450 long, 20 wide at midlength. Glandular oesophagus 1,126 long, with maximum width at mid-length 41 . Vulva at level of body cuticle, $7.2 \mathrm{~mm}$ from anterior extremity. Vagina directed posteriorly, composed of vagina vera 113 long (measured following its lumen), separated by valves and circular musculature from vagina uterina; vagina uterina 161 long, with muscular walls (Fig. 5D). Reproductive system didelphic-amphidelphic, not extending anterior to level of oesophagointestinal junction. Eggs oval, with developed firststage larva, 36-37 $\times 22-23(\mathrm{n}=10)($ Fig. $5 F)$.

\section{Remarks}

Nandi et al. (1985) described Schistogendra pelargopsis from Pelargopsis capensis (L.) (type-host) and Halcyon smyrnensis (L.) in India. The morphology of this species coincides with that of $Q$. tenuis described from the same host in India by Maplestone (1932) (see Table 1). Therefore, we consider these two species synonymous and $S$. pelargopsis becomes a junior synonym of $Q$. tenuis. 
Singh (1949) recorded $Q$. tenuis from Halcyon smyrnensis in India and provided a description of specimens from this host. However, he described the vagina as directed anteriorly, whereas the material collected by Nandi et al. (1985) is characterised by a vagina directed posteriorly. Further studies may reveal whether the material described by Singh (1949) belongs to another species.

\section{Discussion}

Wong \& Lankester (1984) recognised three species within the genus Quasithelazia: Q. tenuis Maplestone, 1932, Q. incisa (Chabaud \& Rousselot, 1956) and $Q$. caproni (Bain \& Chabaud, 1965), all of them parasitic under the koilin lining of the gizzard of kingfishers (Alcedinidae). We follow their concept for the validity and systematic position of this genus. In addition, we consider that the systematic position of several other species of the subfamily Schistorophinae needs to be revised.

Ryzhikov \& Khokhlova (1964) described Viktorocara halcyoni Ryzhikov \& Khokhlova, 1964 based on a few females collected from Halcyon smyrnensis fusca (Boddaert) and Halcyon pileata (Boddaert) in Vietnam. Later on, this species was considered synonymous with $Q$. tenuis [=Viktorocara tenuis (Maplestone, 1932)] by Baruš et al. (1978). However, females of $V$. halcyoni, as described by Ryzhikov \& Khokhlova (1964), are characterised by a tail with a rounded tip, whereas those of $Q$. tenuis have a bluntly pointed tail. In our opinion, $V$. halcyoni should be considered a valid species and we transfer it to the genus Quasithelazia as Q. halcyoni (Ryzhikov \& Khokhlova, 1964) n. comb.

Schmidt \& Kuntz (1971) described Rusguniella microcordonis Schmidt \& Kuntz, 1971 from the gizzard of Halcyon coromanda major (Temminck \& Schlegel) in Taiwan. They distinguished the new species from the other members of Rusguniella based on its small, delicate cordons and the large number of precloacal papillae. Indeed, R. microcordonis can be distinguished from Rusguniella spp., which possess four pairs of preclocal papillae and a collarette-like structure formed by the posterior part of each pseudolabium, with a smooth edge delimiting a groove. These characters are specific for the members of subfamily Seuratiinae (Chabaud, 1975;
Bain et al., 2014). The correspondence between the morphology of $R$. microcordonis and that of "Viktorocara tenuis (Maplestone, 1932) Skrjabin, Sobolev \& Ivashkin, 1965" was emphasised by Schmidt \& Kuntz (1971), who considered that further reexamination may reveal their conspecificity. On the basis of current knowledge of the morphology of Quasithelazia spp., we place this species in Quasithelazia as Q. microcordonis (Schmidt \& Kuntz, 1971) n. comb.

The morphological characters of Schistogendra multipapillata Zhang, 1993, described as a parasite of Tarsiger cyanurus (Pallas) (Passeriformes: Muscicapidae) in China (Zhang, 1993), correspond to the diagnosis of Quasithelazia. Therefore, we consider it as a member of the latter genus and propose Quasithelazia multipapillata (Zhang, 1993) n. comb.

Despite the priority of Quasithelazia over its junior synonym Schistogendra revealed by Wong \& Lankester (1984), Zhang \& An (2002) described Schistogendra oligopapillata Zhang \& An, 2002 from Anas platyrhynchos f. domesticus L. (Anatidae) from Nanjing, China. This species differs from the other members of genus Schistogendra by its well-developed deirids with three or more cusps, short buccal cavity ( $29 \mu \mathrm{m}$ long), four pairs of precloacal papillae, females possessing a short rounded tail and the preequatorial position of the vulva. The morphology of Schistogendra oligopapillata corresponds to that of Streptocara formosensis Sugimoto, 1930 (syn. Streptocara somateriae Rhyzhikov, 1960) described from A. platyrhynchos (=Anas boschas L.) in Japan and subsequently recorded from various Anatidae in Siberia (Russia) and Canada (Sugimoto, 1930; Skrjabin et al., 1965; Gibson, 1968). The only morphological difference between these two species is the position of the vulva, which is located about the level of the anterior and the middle third of the body length in S. oligopapillata whereas, in S. formosensis, the vulva opens at the level of the middle and the posterior third of the body length. The position of the vulva of $S$. oligopapillata does not correspond to that of any other known acuariid species, which are characterised by the vulva being situated at the mid-body level or posteriorly to it. We consider this species as a species incertae sedis.

On the basis of the review of the known species, we propose the following amended diagnosis of the genus. 


\section{Quasithelazia Maplestone, 1932}

\section{Diagnosis}

Small to medium-sized acuariid nematodes. Anterior end with 2 pseudolabia, each bearing single amphid and pair of papillae. One subventral and one subdorsal lobe on each pseudolabium present, formed by transverse incision. Anterior cuticular ornamentation in form of cordons, collarette or ptilina absent. Pseudolabia absent. Deirids small and simple, situated anterior to nerve-ring. Excretory pore anterior or posterior to nerve-ring. Lateral alae present or absent. Buccal cavity long, with conspicuous cross-striations. Muscular and glandular oesophagus clearly distinct. Tail conical, with pointed or rounded tip. Phasmids subterminal. Male: with caudal alae; precloacal pairs of papillae numerous (known range from 10 to 16), arranged equidistantly; single median sessile papilla present; postclocal papillae consisting of five pairs of pedunculate papillae and one pair of sessile papillae situated at base of last pedunculate pair of papillae or between last two pedunculate pairs; area rugosa absent, left spicule long, consisting of handle and blade, right spicule short and robust. Female: vulva from equatorial to postequatorial; vagina vera short, separated from short, muscular vagina uterine by well-developed circular musculature, valves may be present; uteri didelphic-amphidelphic. Under koilin lining of the muscular stomach of Alcedinidae and passerine birds (Muscicapidae). Type-species: Q. tenuis Maplestone, 1932.

At present, the following species correspond to the generic diagnosis of Quasithelazia:

- Q. tenuis Maplestone, 1932 (type-species) (=Schistogendra pelargopsis Nandi, De \& Majumdar, 1985, new synonymy) from Halcyon smyrnensis (L.) (type-host) and Pelargopsis capensis (L.) (Alcedinidae) in India (Maplestone, 1932; Singh, 1949; Nandi et al., 1985);

- Q. incisa (Chabaud \& Rousselot, 1956) Wong \& Lankester, 1984 from Halcyon senegalensis (L.) in Congo (Chabaud \& Rousselot, 1956);

- Q. caproni (Bain \& Chabaud, 1965) Wong \& Lankester, 1984 from Corythornis madagascariensis (L.) (Alcedinidae) in Madagascar (Bain \& Chabaud, 1965);

- Q. halcyoni (Ryzhikov \& Khokhlova, 1964) n. comb. from $H$. smyrnensis (L.) and Halcyon pileata (Boddaert) in Vietnam (Ryzhikov \& Khokhlova, 1964; Parukhin, 1964) and from $H$. pileata in Rimsky-Korsakov Archipelago (Russian Far East) (Alekseev \& Smetanina, 1968);

- Q. microcordonis (Schmidt \& Kuntz, 1971) n. comb. from Halcyon coromanda major (Temminck \& Schlegel) in Taiwan (Schmidt \& Kuntz, 1971);

- Q. multipapillata (Zhang, 1993) n. comb. from Tarsiger cyanurus (Pallas) (Muscicapidae) in China (Zhang, 1993);

- Q. rostrata n. sp. from Ceyx erithaca (L.) (typehost) and Alcedo euryzona Temminck, 1830 (Alcedinidae) in Malaysia (present study);

- Q. alata n. sp. from Enicurus ruficapillus Temminck (Muscicapidae) in Malaysia (present study).

Our SEM study of $S$. rostrata revealed that two pairs of plate-like teeth are situated on the internal side of the pseudolabia but there are no distinct sublabia. A similar organisation of the cephalic region is known for the members of Ancyracanthopsis Diesing, 1861 of the subfamily Schistorophinae (see Wong \& Lankester, 1985a; Wong \& Anderson, 1990). All other genera of the subfamily Schistorophinae are characterised by the presence of two ventral and two dorsal sublabia armed with teeth, i.e. Viktorocara (see Wong \& Lankester, 1984), Molinacuaria Wong \& Lankester, 1985 (see Adams \& Gibson, 1969; Wong \& Lankester, 1985a), Sciadiocara Skrjabin, 1916 (see Wong \& Lankester, 1985b), Sobolevicephalus Parukhin, 1964 (see Wong \& Lankester, 1985c) and Schistorophus Railliet, 1916 (see Petter, 1966). Although the teeth of Schistogendra and Ancyracanthopsis are not situated on the sublabia, they are probably homologous to those of the other genera within the Schistorophinae. Amongst the other two subfamilies of the Acuariidae, similar teeth have been documented for Ingliseria (Seuratiinae) only (Diaz et al., 2009).

The genera of the subfamily Schistorophinae are parasitic mainly in birds of the families Charadriidae, Scolopacidae (Charadriiformes), Alcedinidae (Coraciiformes) and Rallidae (Gruiformes) inhabiting freshwater or saline wetlands, and only few members of Molinacuaria, Quasithelazia and Viktorocara are parasitic of terrestrial birds of Passeriformes or Galliformes (Wong \& Lankester, 1984, 1985a, b, c; Wong \& Anderson, 1990; Mutafchiev et al., 2009; present study). This suggests that Schistorophinae has 
a primarily aquatic life-cycle. Both $Q$. multipapillata and $Q$. alata differ from the other six members of Quasithelazia with their hosts belonging to the family Muscicapidae as well as by having 16 pairs of precloacal papillae instead of 10-14 pairs. The latter character is probably a synapomorphy for the parasites of flycatchers.

Acknowledgements This study was supported by SciexHMS $^{\text {ch }}$ Program CRUS, Switzerland. The re-examination of the type material of Schistogendra pelargopsis was possible due to a SYNTHESYS 2 (EC FP7) visit grant FR-TAF-841 to the senior author, kindly hosted by Dr O. Bain. We are grateful to Prof. Rosli Hashim and Prof. Rosli Ramli, Institute of Biological Sciences, Faculty of Sciences, University of Malaya, Kuala Lumpur, for their kind assistance in the organisation of the field studies and for making available facilities of the Gombak Biological Station. The field trip of JM and BBG in Malaysia was in the frames of a project supported by the National Science Foundation, USA (PBI Awards No. 0818696 to Prof. Janine N. Caira and No. 0818823 to Prof. Kirsten Jensen).

\section{References}

Adams, J. R., \& Gibson, G. G. (1969). Ancyracanthopsis bendelli $\mathrm{n}$. sp. (Acuariidae: Schistorophinae) from Pacific Coast grouse, with observations on related nematode genera. Canadian Journal of Zoology, 47, 619-626.

Alekseev, V. M., \& Smetanina, Z. B. (1968). Nematode of fisheating birds of Rimsky-Korsakov Archipelago. In Skrjabin, K. I. \& Mamaev, Y. L. (Eds) Gel'minty Zhivotnykh Tikhogo okeana. Moscow: Nauka, pp. 97-104 (In Russian).

Bain, O., \& Chabaud, A. G. (1965). Spirurides parasites d'Oiseaux Malgaches (Troisième note). Bulletin du Muséum National d'Histoire Naturelle, 2e Série, 37, 173-185.

Bain, O., Mutafchiev, Y., \& Junker, K. (2014). Order Spirurida. In: Schmidt-Rhaesa, A. (Ed.) Handbook of Zoology. Volume 2. Nematoda. Berlin: De Gruyter, pp. 661-732.

Baruš, V., Sergeeva, T. P., Sonin, M. D., \& Ryzhikov, K. M. (1978). Helminths of Fish-Eating Birds of the Palaearctic Region. I. Moscow-Prague: Academia, 319 pp.

Chabaud, A. G. (1975). Keys to the genera of the order Spirurida. Part 2. Spiruroidea, Habronematoidea and Acuarioidea. In: Anderson, R. C., Chabaud, A. G., \& Willmott, S. (Eds) CIH keys to the nematode parasites of vertebrates, No. 3. Farnham Royal: Commonwealth Agricultural Bureaux, pp. 29-58.

Chabaud, A. G., \& Rousselot, R. (1956). Description d'un nouvel Acuariide d'Afrique Equatoriale: Schistogendra incisa n. gen., n. sp. Annales de Parasitologie Humaine et Comparée, 31, 242-247.

Chitwood, B. G., \& Wehr, E. E. (1934). The value of cephalic structures as characters in nematode classification, with special reference to the superfamily Spiruroidea. Zeitschrift für Parasitenkunde, 7, 273-335.

Diaz, J. I., Cremonte, F., Navone, G. T., \& Laurenti, S. (2005). Adults and larvae of Skrjabinocerca canutus n. sp.
(Nematoda: Acuariidae) from Calidris canutus rufa (Aves: Scolopacidae) on the southern Southwest Atlantic coast of South America. Systematic Parasitology, 60, 113-123.

Diaz, J. I., Fonteneau, F., Panisse, G., Cremonte, F., \& Navone, G. T. (2009). Redescription of Ingliseria cirrohamata (Linstow, 1888) (Nematoda: Acuariidae), including new hosts and geographical records. Journal of Parasitology, 95, 396-402.

Gibson, G. G. (1968). Species composition of the genus Streptocara Railliet et al., 1912 and the occurrence of these avian nematodes (Acuariidae) on the Canadian Pacific coast. Canadian Journal of Zoology, 88, 629-645.

Maplestone, A. (1932). Parasitic nematodes obtained from animals dying in the Calcutta Zoological gardens. Parts 9-11. Records of the Indian Museum, 34, 229-261.

Mutafchiev, Y., \& Georgiev, B. B. (2010). The erection of Pelecanema n. g. (Nematoda: Spirurida: Acuariidae), with redescriptions of Pelecanema sirry (Khalil, 1931) n. comb. and P. pelecani (Johnston \& Mawson, 1942) n. comb. Systematic Parasitology, 77, 45-54.

Mutafchiev, Y., Halajian, A., \& Georgiev, B. B. (2010). Two new nematode species of the genus Cosmocephalus Molin, 1858 (Spirurida: Acuariidae), with an amended generic diagnosis and an identification key to Cosmocephalus spp. Zootaxa, 2349, 1-20.

Mutafchiev, Y., Zehtindjiev, P., \& Georgiev, B. B. (2009). First record of the nematode Aviculariella alcedonis (Yamaguti \& Mitunaga, 1943) (Spirurida, Acuariidae) in Europe, with SEM observations and comments on its taxonomic position. Acta Parasitologica, 54, 374-379.

Nandi, A. P., De, N. C., \& Majumdar, G. (1985). Records of two new nematodes (Acuariidae) parasitizing kingfishers (Coraciiformes) of West Bengal, India. Helminthologia, 22, 161-169.

Parukhin, A. M. (1964). Occurrence of males of Viktorocara halcyoni Rhyzhikov et Khokhlova, 1964 (Nematoda: Acuariidae). Materialy $k$ Nauchnoy Konferencii Vsesouyuznogo Obshtestva Gel'mintologov, 2, 52-59 (In Russian).

Petter, A. J. (1966). Trois espèces d'Acuariidae parasites du gésier de Numenius phaeopus à l'île Europa. Bulletin du Muséum National d'Histoire Naturelle, 2e Série, 38, 940-948.

Ryzhikov, K. M., \& Khokhlova, I. G. (1964). Two new nematode species (Schistorophus cirripedesmi sp. nov. and Viktorocara halcyoni sp. nov.) from free-living birds in Vietnam). Helminthologia, 5, 107-114 (In Russian).

Schmidt, G., \& Kuntz, R. E. (1971). Nematode Parasites of Oceanica. XV. Acuariidae, Streptocaridae, and Seuratidae of Birds. Proceedings of the Helminthological Society of Washington, 38, 217-223.

Shikhobalova, N. (1930). On a new genus of the nematode fam. Acuariidae Seurat, 1913. Journal of Parasitology, 16, 220-223.

Singh, S. N. (1949). Studies on the helminth parasites of birds in Hyderabad State. Nematoda III. Journal of Helminthology, $23,25-38$.

Skrjabin, K. I., Sobolev, A. A., \& Ivaskin, V. M. (1965). [Spirurata of animals and man and the diseases caused by them. Part 3. Acuarioidea]. In: Skrjabin, K. I. (Ed.) Osnovy Nematologii, Vol. 14. Moscow: Nauka, 572 pp (In Russian). 
Sugimoto, M. (1930). On a new nematode parasite (Streptocara formosensis sp. nov.) in the gizzard of Formosan domestic duck. Japanese Society for Tropical Agriculture, 2, 135-144.

Wong, P. L., \& Anderson, R. C. (1990). Ancyracanthopsis winegardi n. sp. (Nematoda: Acuarioidea) from Pluvialis squatarola (Aves: Charadriidae) and Ancyracanthopsis heardi $\mathrm{n}$. sp. from Rallus longirostris (Aves: Rallidae), and a review of the genus. Canadian Journal of Zoology, 68, 1297-1306.

Wong, P. L., \& Lankester, M. W. (1984). Revision of the genus Viktorocara Guschanskaya, 1950 (Nematoda: Acuarioidea). Canadian Journal of Zoology, 62, 2541-2549.

Wong, P. L., \& Lankester, M. W. (1985a). Revision of the genus Ancyracanthopsis Diesing, 1861 and description of a new genus Molinacuaria n. gen. (Nematoda: Acuarioidea). Canadian Journal of Zoology, 63, 1556-1564.

Wong, P. L., \& Lankester, M. W. (1985b). Revision of the genus Sciadiocara Skrjabin, 1916 (Nematoda: Acuarioidea). Canadian Journal of Zoology, 63, 1565-1575.

Wong, P. L., \& Lankester, M. W. (1985c). Revision of the genus Sobolevicephalus Parukhin, 1964 (Nematoda: Acuarioidea). Canadian Journal of Zoology, 63, 1576-1581.

Zhang, L.-P. (1993). The first record of the genus Schistogendra from China, with description of a new species. Wuyi Science Journal, 10, 26-28 (In Chinese).

Zhang, L.-P., \& An, R.-Y. (2002). A new species of genus Schistogendra parasitizing the domestic duck, Anas platyrhynchos domesticus from Nanjing, China. Acta Zootaxonomica Sinica, 27, 42-45. 